\title{
Assessment of Nutritional Status Using Anthropometric Methods: A Study of Rural and Urban Primary Children in Coastal Belt of Bangladesh
}

\author{
Md. Sagirul Islam Majumder ${ }^{1, ~ *, ~ H e d a y t u l ~ I s l a m ², ~ M u n n a f ~ H o s s e n ~}{ }^{2}$, Jashim Uddin ${ }^{3}$, Irteja Hasan ${ }^{4}$, \\ Md. Abdur Rouf Talukder ${ }^{5}$, Md. Apu Sarowar ${ }^{6}$, Mustafizur Rahman ${ }^{7}$, Israt Sultana ${ }^{8}$ \\ ${ }^{1}$ The United Graduate School of Agricultural Science, Kagoshima University, Kagoshima, Japan \\ ${ }^{2}$ Deptartment of Environmental Sanitation, Patuakhali Science and Technology University, Patuakhali, Bangladesh \\ ${ }^{3}$ Deptartment of Nutrition and Diabetics, Patuakhali Science and Technology University, Patuakhali, Bangladesh \\ ${ }^{4}$ Deptartnent of Geo-Information Science and Earth Observation, Patuakhali Science and Technology University, Patuakhali, Bangladesh \\ ${ }^{5}$ Institute of Social Welfare and Research, Dhaka University, Dhaka, Bangladesh \\ ${ }^{6}$ Department of Public Administration, Dhaka University, Dhaka, Bangladesh \\ ${ }^{7}$ Agriculture Training Institute, Faridpur, Bangladesh \\ ${ }^{8}$ Bangladesh Coastal Development Foundation, Dhaka, Bangladesh
}

Email address:

sagir_mjd@yahoo.com (Md. S. I. Majumder)

${ }^{*}$ Corresponding author

\section{To cite this article:}

Md. Sagirul Islam Majumder, Hedaytul Islam, Jashim Uddin, Munnaf Hossen, Irteja Hasan, Md. Abdur Rouf Talukder, Md. Apu Sarowar, Mustafizur Rahman, Israt Sultana. Assessment of Nutritional Status Using Anthropometric Methods: A Study of Rural and Urban Primary Children in Coastal Belt of Bangladesh. Biochemistry and Molecular Biology. Vol. 2, No. 5, 2017, pp. 54-59.

doi: $10.11648 /$ j.bmb.20170205.11

Received: April 30, 2017; Accepted: June 12, 2017; Published: September 30, 2017

\begin{abstract}
This study deals with the assessment of nutritional status of rural and urban primary school going children in coastal belt of Bangladesh. Anthropometric data were collected from anthropological survey among 200 participants of twenty primary schools. Ten of these were from urban area and ten were from rural area and equal percentages of participants were taken from boys and girls who were selected randomly. The study found that rural school going children suffering more from under nutrition (Stunting, wasted, and underweight) problem where overweight and obesity is the major problem for urban children. It is also found that the health status of boys is slightly better than girls from rural area. Such as in rural area percentages of underweight girls are more than boy. But in case of urban area of Barisal the nutritional condition of girls is better than the boys. The study found remarkable deference of nutritional between rural and urban girls. Thinness and underweight is the major problem for rural girls but it is less in urban girls.
\end{abstract}

Keywords: Nutritional Status, Anthropometric Methods, Rural and Urban Primary Children, Coastal Belt

\section{Introduction}

Anthropometry has become a practical tool for evaluating the nutritional status of populations, particularly of children in developing countries "[5]" and nutritional status is the best indicator of the global well- being of children "[5]". One of the major global health problem faced by the developing countries, today is malnutrition "[17], [19]". Bangladesh is a south Asian developing country. The economic improvements in South Asian countries over the past decade have not been adequately reflected in improvements in child nutrition "[1-2], [4]". Malnutrition not only makes the child more vulnerable to morbidity and mortality "[3], [9]" but has been linked to poorer educational attainment, delayed mental development "[11]" and lower intellectual and physical abilities in adult life "[14]". Poor fetal growth and/or undernourishment in the early child years lead to irreversible damage causing shorter adult height as well as lower weight "[16]". Height-for-age and weight-for-age thus measure child 
growth relative to its potential, reflecting chronic and acute nutritional deprivation"[7]". Study shows that in Bangladesh, malnutrition is one of the major causes of childhood illness and mortality "[23]". Vulnerable populations like school children are susceptible to health problems associated with micronutrient deficiencies. The middle childhood, 6 to 12 years old, is a period of steady physical growth "[6]". This age is also the period of major cognitive development. Their brain reaches nearly adult size by the end of primary-school age during this period, life pattern and habits are established and it will become the ground where the quality of life it going to be ground. School going children's are one of the vulnerable group to malnutrition and health problems related with nutrient deficiencies "[12]".

Due to the complexity and variety of malnutrition problems among and within countries and other geographical and social strata, the precise causes of malnutrition are accordingly specific. Nevertheless, United Nations International Children's Emergency Fund (UNICEF) has adopted a model "[15]" that can be used in various situations to explain the causes of malnutrition. In this model, malnutrition (and death) results from either inadequate nutrient intake or disease both of which are brought about by one or a combination of three interrelated conditions: inadequate household food security, inadequate maternal and child care and insufficient health services and an unhealthy environment. These underlying causes have a base in the social, political and economic environment that determines the utilization of potential resources "[8]".

There are 78,126 primary schools in Bangladesh, serving 17.6 million children "[18]". At past there have observed more underweight problem among them but with the development of life style and income in this century overweight is also a major problem for urban kindergarten going children. So this study gave emphasize not only on under nutrition but also on over nutrition. Other impotent objectives of this study are to find out the difference between nutritional status of boys and girls, urban and rural students.

\section{Methodology}

A cross sectional sample survey was carried out among 200 students of ten primary schools of Barisal district of Bangladesh which is located at southern part. Ten of them are from urban area. They are 'Amrita Lal Dey Kindergarten' and 'Mollica kindergarten' etc. Another ten schools are from rural area. They are 'Ray Pasha govt. primary school' and 'Uttor Karapur govt. primary school' etc. This methodology was chosen as it would show the nutritional status and factors affecting it of the primary school going children at a point in time. The study populations were under class five students age 6-10 years. There randomly 10 students were selected from every class from each class one to class five. The anthropometric data were collected based on standard methods. A digital weighing machine was used to record the weight of the study person. The respondents should stand on the machine with bare feet. Height of the respondents were measured bare footed in the standing position with a standard scale to the nearest $0.1 \mathrm{~cm}$. For data analysis Z-scores are used which are widely used as a "system for analysis and interpreting of anthropometric measurements" [20]. Further $\mathrm{Z}$-score are gender and age independent, thus permitting the presentation of children's growth status by combining both males and females. The three anthropometric indices can be expressed as weight for age Z-scores (WAZ), height for Age Z-scores (HAZ) and Weight for Height Z-scores (WHZ) which is also known as Body Mass Index (BMI) is commonly used to classify underweight, overweight and obesity. It is defined as the weight in kilograms divided by the square of the height in meters $\left(\mathrm{kg} / \mathrm{m}^{2}\right)$ "[20]". All of the statistical analysis and all other data processing were done by using Microsoft word 2010 and Microsoft Excel 2010 for tabular, charts and graphical representation.

$$
\text { BMI }=\frac{\text { Weight in kilogram }}{\text { Height in } \text { meters }^{2}}
$$

\section{Result and Discussion}

\subsection{Family Income Level}

Family income level is one of the major causes of malnutrition. This study shows that there are huge difference between rural and urban family income level. As most of the rural family income comes from agricultural production and small business, $38 \%$ family income level is under five thousand and $45 \%$ family income level is in five thousand to ten thousand. On the other hand there have some people who are servicemen and emigrants. So, there are $12 \%$ family who have income between eleven thousand to fifteen thousand, where only $5 \%$ family income level is more than fifteen thousand.

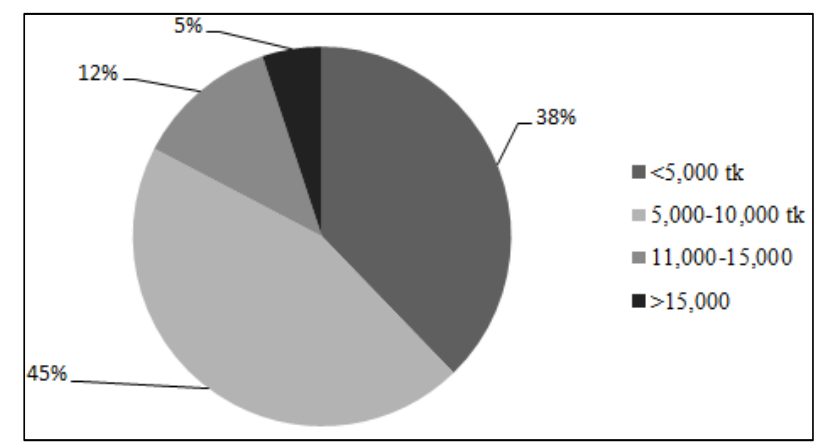

Figure 1. Family income level of rural primary school going children.

In contrast most of the urban family income depends on job and business. So the income level of urban families is higher than rural family. Figure 2 shows that $27 \%, 41 \%$ and $21 \%$ urban family have income from ten to twenty thousand, twenty one to thirty thousand and thirty one to forty thousand respectively. Again only $6 \%$ families have income less than ten thousand. There have also 5\% families who have income more than forty thousand. In addition with urban male family member a huge amount of female member are engaged in job, on the other hand a few female of rural family engaged in job. 


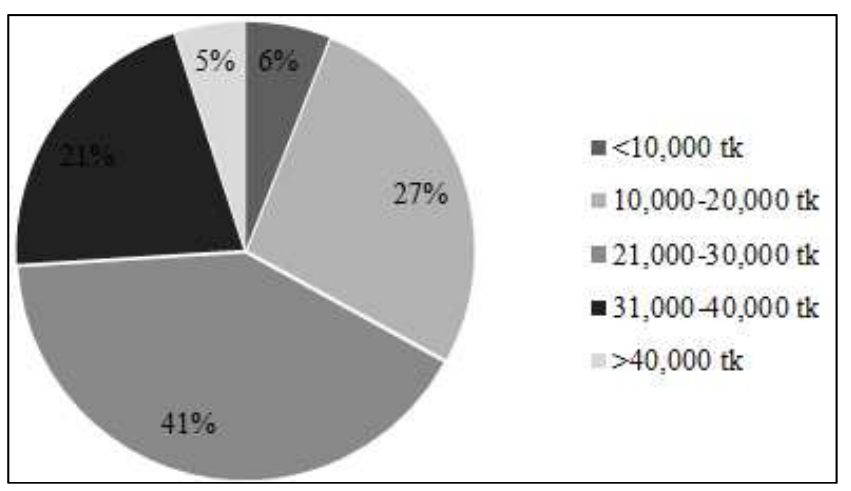

Figure 2. Family income level of urban primary school going children.

\subsection{Comparison Analysis of Nutritional Status of Rural and Urban Primary School Going Children}

\subsubsection{Height for Age}

In this study growth was measured in height and compared between urban and rural area. The figure 3 showed that stunting is major problem in rural area but in urban area around $17 \%$ students are suffering from stunting. The study found that poverty and lack of nutrition education are the main causes of Stunting. On the other hand over height students are more in urban area but in rural area it is only about $7 \%$. It is also significant that normal height children are more in urban area than rural area $(27 \%)$. This is due to increase consciousness about health in urban area.

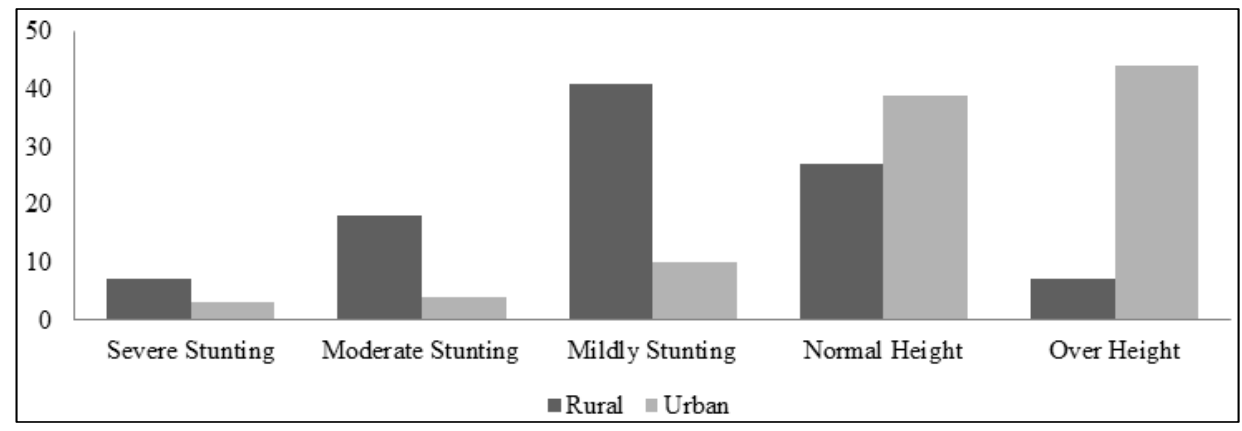

Figure 3. Comparison analysis of nutritional status (Based on height for age Z score).

\subsubsection{Weight for Height}

According to weight for height measurement the statistics is near same as height for age. The figure 4 showed that near about $6 \%$ rural primary school going children and $2 \%$ urban primary school going children were severely wasted. $17 \%$ in rural and $6 \%$ in urban were moderate wasted, $42 \%$ in rural and $12 \%$ in urban are mildly wasted, $7 \%$ in rural and $42 \%$ in urban were over height. Whereas, about $28 \%$ students in rural out of 100 students and 38\% students in urban out of 100 students were gained normal height against their age groups. Low economic condition and lack of education are the main causes for poor health condition of rural children. Moreover infectious diseases and unhygienic sanitary condition affects the rural child health.

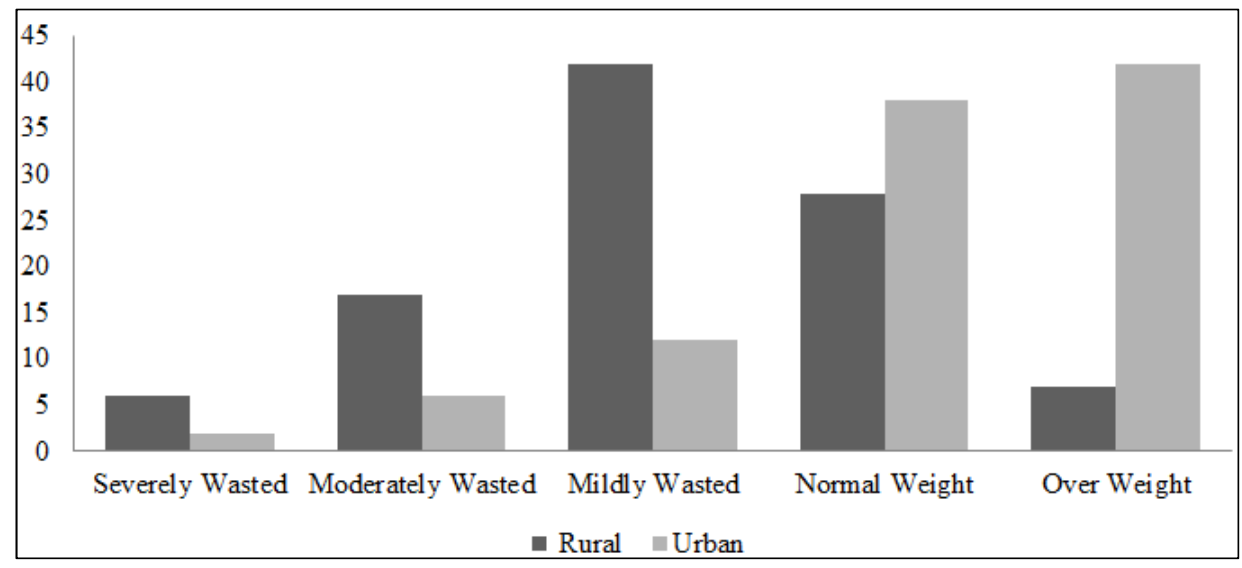

Figure 4. Comparison analysis of nutritional status (Based on weight for height Z score).

\subsubsection{Weight for Age}

Weight also has a strong relationship considering with age. According to figure 5, it is found that around 6\% rural primary school going children and $2 \%$ urban primary school going children were severely underweight. Where about $18 \%$ in rural and 5\% in urban were moderate underweight, $41 \%$ in rural and $9 \%$ in urban are mildly underweight, $31 \%$ in rural and $41 \%$ in urban were normal and $4 \%$ in rural and $34 \%$ in urban were overweight. That means rural children are still suffering more from underweight but urban children faces overweight problem. With the civilization urban children are mostly fond of junk food and computer based game rather than physical activities. Those two are the main causes of increasing overweight of urban children. 


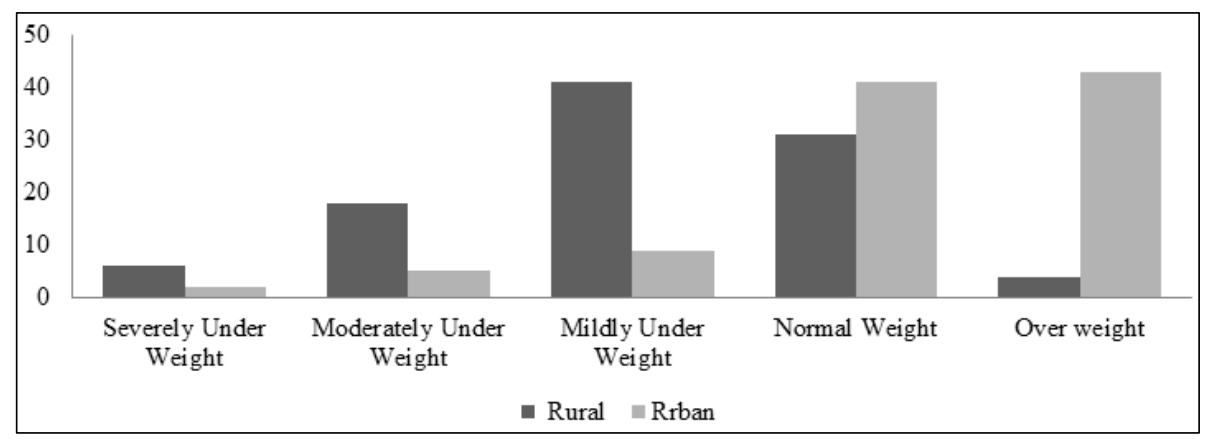

Figure 5. Comparison analysis of nutritional status (Based on weight for age Z score).

\subsection{Body Mass Index (BMI) Calculation}

\subsubsection{Comparison Analysis of Nutritional Status of Rural and Urban Children}

BMI is the most used method for anthropometric measurement all over the world. According to BMI it is found that large amount of rural children of the selected area are suffering from thinness. The figure 6 showed that near about $66 \%$ rural children are suffering from thinness $(7 \%$ severe thinness, $16 \%$ moderate thinness, $43 \%$ mild thinness). The main causes of thinness of rural children are inadequate feeding practices, infectious diseases and poor family condition. But in case of urban children it is only $19 \%(3 \%$ severe thinness, $5 \%$ moderate thinness, $11 \%$ mild thinness). On the other hand overweight becoming a major problem for urban children as about $42 \%$ of urban children are overweight. The main causes of overweight are more fast food consumption, lack of physical activities and social status. Ignorance of parents is also associate cause of overweight of urban children.

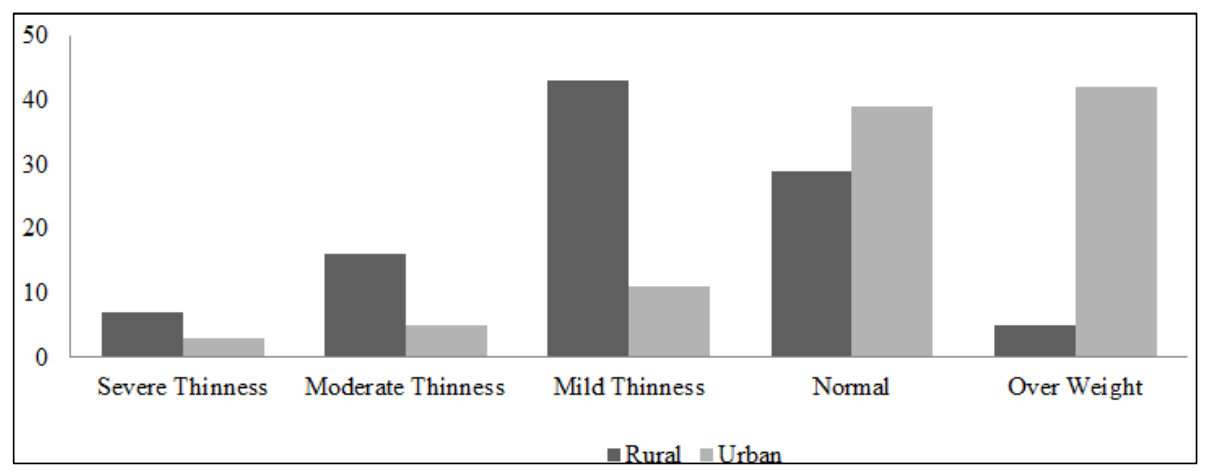

Figure 6. Comparison analysis of nutritional status of rural and urban children (Based on BMI for age Z score).

\subsubsection{Comparison Analysis of Nutritional Status of Rural Boys and Girls}

Figure 7 shows the comparison analysis of nutritional status of rural boys and girls. It represent that thinness is major problem in rural area. Girls are suffering more than the boys. Near about $70 \%$ ( $8 \%$ severe thinness, $18 \%$ moderate thinness, $44 \%$ mild thinness) girls are suffering from thinness where percentage of boys is around 62\% (6\% severe thinness, $14 \%$ moderate thinness, $42 \%$ mild thinness). On the other hand percentage of overweight children in rural area is very low ( $6 \%$ boys and $4 \%$ girls). The underlying causes of thinness of rural girls are gender discrimination, lack of knowledge, large family size and superstitious belief.

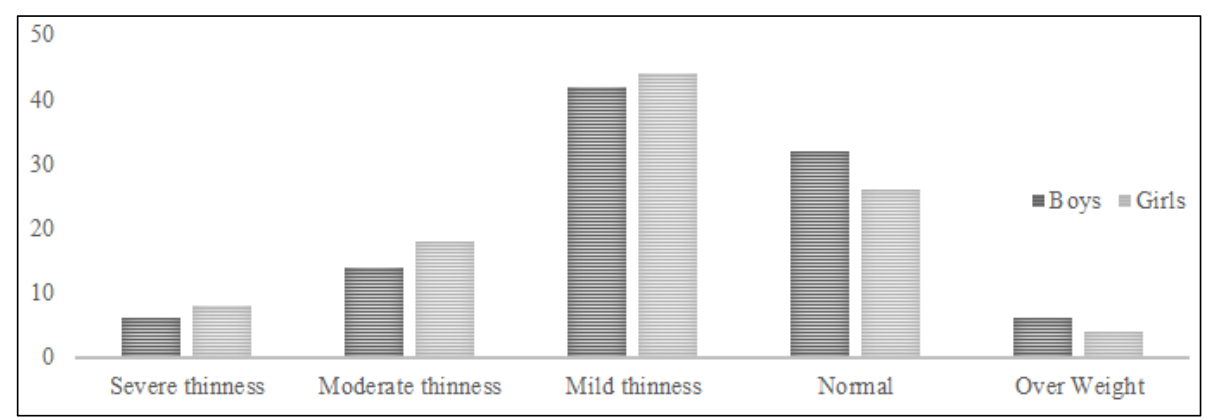

Figure 7. Comparison analysis of nutritional status of boys and girls of rural children (Based on BMI for age Z score). 


\subsubsection{Comparison Analysis of Nutritional Status of Urban Boys and Girls}

In urban area thinness is not major problem for children (Figure 8 ). Only $18 \%$ boys ( $2 \%$ severe thinness, $4 \%$ moderate thinness, $12 \%$ mild thinness) are thin according to BMI. But the main and major problem is overweight problem. About $48 \%$ boys and $36 \%$ girls of urban area are overweight where around $34 \%$ boys and $44 \%$ girls are normal on the basis of BMI.

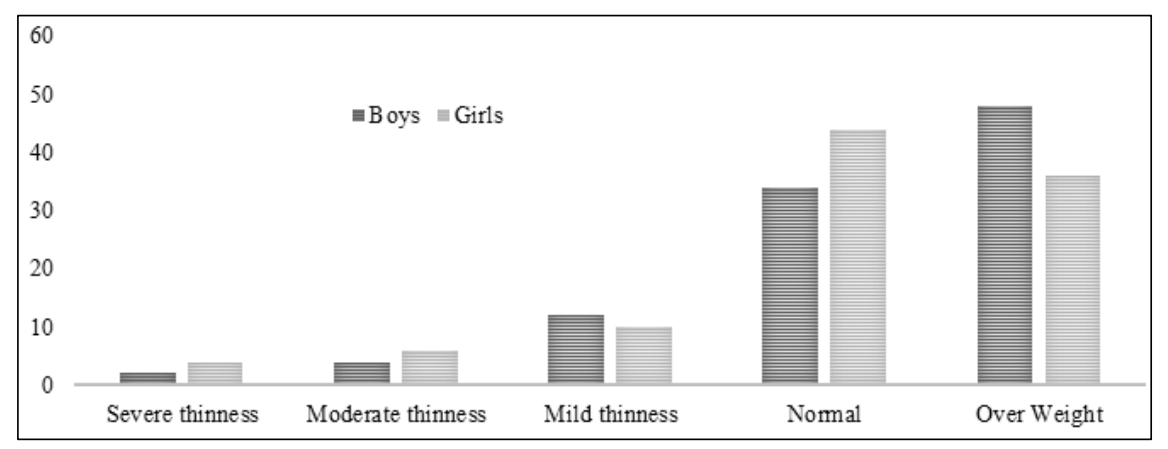

Figure 8. Comparison analysis of nutritional status of boys and girls (Based on BMI for age Z score).

\subsubsection{Comparison Analysis of Nutritional Status of Rural and Urban Girls}

Figure 7 shows that the nutritional condition of rural and urban girls is in inverse position. Though most of the urban girls are normal $(44 \%)$ or overweight (36\%), only $26 \%$ and $4 \%$ of rural girls are normal and overweight consecutively. On the other hand thinness is the major problem in rural area. About $70 \%$ of rural girls $(8 \%$ severe thinness, $18 \%$ moderate thinness, $44 \%$ mild thinness) face thinness problem where only $20 \%$ urban girls (4\% severe thinness, $6 \%$ moderate thinness, $10 \%$ mild thinness) face this problem.

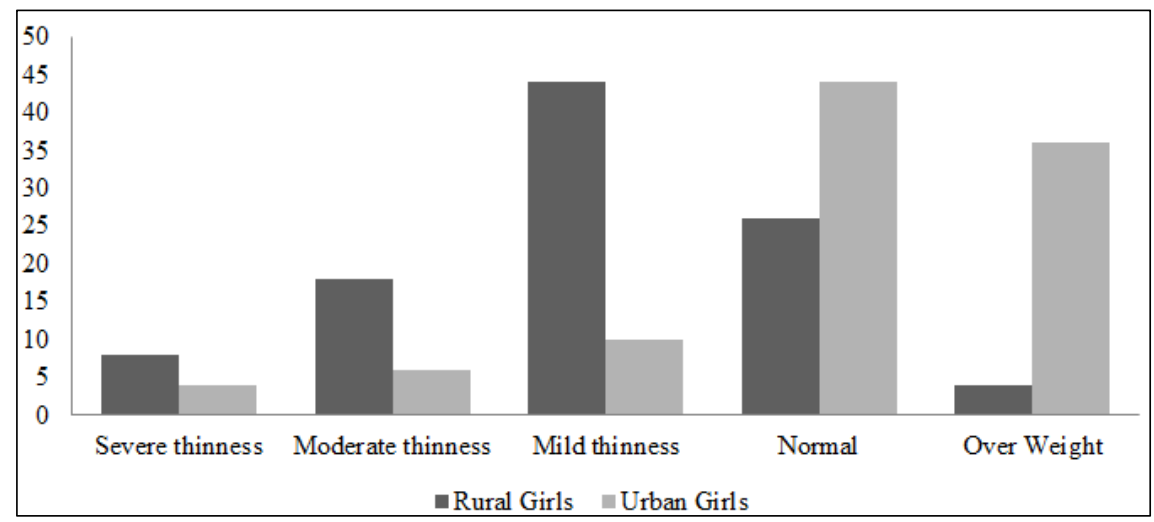

Figure 9. Comparison analysis of nutritional status of rural and urban girls (Based on BMI for age $Z$ score).

\section{Conclusion}

Bangladesh is a developing country with a significant problem of malnutrition. Barisal is the area of southern part of Bangladesh which is near the Bay of Bengal. The costal rural people are deprived from development although the city people are blessed with development. So the urban children play more computer based game than physical games. Not only that but also they like fast-food which is high in fat. According to the World Health Organization (WHO) data, around 1 billion people are overweight in the world today [22]. Each year around 2.6 million people lose their lives as a result of problems caused by overweight or obesity. Contrary to common belief, obesity is not only associated with countries with high income levels but also it has become a threat to lower and medium size economies. In this study the result has indicated that overweight and obesity is the main problem for urban school going children of Barisal as near about $46 \%$ boys and $38 \%$ girls are overweight. On the other hand rural people are not concern about their child health except some educated family. So under nutrition is still the main problem for rural children. This study reported that near about $62 \%$ boys and $70 \%$ girls from rural area suffering from thinness (severe thinness, moderate thinness, mild thinness). It is also observed that rural girls are more affected from under nutrition than rural boys or urban girls. Therefore, prevention of malnutrition should be given a high priority by the government and NGO to the rural primary school children. They should also concern about urban children as overweight condition is increasing there.

\section{References}

[1] Amogo $\mathrm{H}$ et. al. 2001: Growth defects in chilean school children. Journal of Nutrition 131: 251-254. 
[2] Das Gupta M. 1990: Death clustering, mothers' education and the determinants of child mortality in rural Punjab, India. Popul Stud.; 44(3): 489- 505.

[3] Fenske N, Burns J, Hothorn T, Rehfuess EA. 2013: Understanding child stunting in India: a comprehensive analysis of socio-economic, nutritional and environmental determinants using additive quantile regression. PLOS One. DOI: 10.1371 journal. pone.0078692.

[4] Glewwe P. 1999: Why does mother's schooling raise child health in developing countries? Evidence from Morocco, J Human Resour.; (35)1: 124- 159.

[5] Hakeem R, Shaikh AH, Asar F 2004: Assessment of linear growth of affluent.

[6] Isaranurug 1999: S. Child and adolescent health promotion and protection in congested area of Bangkok metropolis; watmakok community. Bangkok: Mahidol Universsity. Pp. 57101.

[7] Lanjouw P, Ravallion M. 1995: Poverty and household size. Econ J.; 105(433): 1415 -1434.

[8] Maxwell S and Smith M 1992: "Household Food Security: A concept review", Part 1 in Maxwell S and Frankenberger T (eds). Household Food Security: Concepts, indicators, measurements. A technical review, United Nations International Fund for Agricultural Development, New York and Rome.

[9] Mendez MA, Adair LS. 1999: Severity and timing of stunting in the first two years of life affect performance on cognitive tests in late childhood. J Nutr.; 129(8): $1555-62$.

[10] Mohamed H Bahbah, EL-Sayed I Slama, Abd-El Hafiz M Ramadan MD, Mohamed A Abo Zeed 2015: Prevalence of obesity and overweight in primary school children living in Menoufia governorate, Menouf district. pp- 73.

[11] Moestue H, Huttly S. 2008: Adult education and child nutrition: the role of family and community. J Epidemiol Community Health. 62(2): $153-9$.
[12] Nelson We, Behman RE, Kligmen RM 1996: Arvir AM. Editors' textbook of pediatric $15^{\text {th }}$ ed. Philadelphia. WB Sauders. pp 56-72.

[13] Onis Mde, Frongillo EA, Blossner M 2000: Is malnutrition declining? An analysis of change in levels of child malnutrition since 1980. Bull World Health Organ, 10: 1222-1223.

[14] Siddiqi MN, Haque MN, Goni M. 2011: Malnutrition of under-five children: Evidence from Bangladesh. Asian J Med Sci.; 2(2): 113-9.

[15] The International Classification of adult underweight, overweight and obesity according to BMI (Adapted from WHO 1995, WHO 2000, WHO 2004).

[16] Unger A. 2011: Children's health in slum settings, archives of disease in childhood; 2013. DOI: 10.1136/archdischild301621 .

[17] UNICEF Policy Review 1990: Strategy for improved nutrition of children and women in developing countries. UNICEF, New York: USA; 5-36.

[18] UNICEF 2006: State of World's Children. UNICEF, New York.

[19] World Health Organization Expert Committee 1985: An estimate for the prevalence of child malnutrition in developing countries. World Health Stat Q, 38: 331-347.

[20] WHO 1995: Physical status: the use and interpretation of anthropometry. Report of a WHO expert consultation. Geneva, World Health Organization (WHO).

[21] WHO 2007: Height for age (Z score) girls, boys; Weight for age ( $\mathrm{Z}$ score) girls, boys; Weight for height ( $\mathrm{Z}$ score) girls, boys; BMI for age ( $\mathrm{Z}$ score) Girls, Boys.

[22] World Health Organization 2011: Obesity and overweight. WHO Fact Sheet Number 311, Geneva.

[23] World Bank (WB) 2006: Repositioning nutrition as central to development: a strategy for Logescale action. World Bank Nutrition Strategy Paper. Washington, DS: World Bank. 